\title{
Evaluation of superficial microhardness in dental enamel with different eruptive ages
}

\section{Dafna Geller Palti ${ }^{(a)}$ \\ Maria Aparecida de Andrade \\ Moreira Machado(b) \\ Salete Moura Bonifacio da Silva ${ }^{(c)}$ \\ Ruy Cesar Camargo Abdo (d) \\ José Eduardo de Oliveira Lima ${ }^{(b)}$}

(a) Graduate student; (b) Associate Professors; (c) PhD, Professor; (d) Chair Professor

- Department of Pediatric Dentistry,

Orthodontics and Public Oral Health,

School of Dentistry of Bauru, University of São Paulo, Bauru, SP, Brazil.
Corresponding author:

Dafna Geller Palti

Departamento de Odontopediatria

Faculdade de Odontologia da USP

Al. Octávio Pinheiro Brisola, 9-75

Bauru - SP - Brazil

CEP: 17012-901

E-mail:dafna_geller@yahoo.com

Received for publication on May 22, 2007

Accepted for publication on Oct 29, 2007

\begin{abstract}
This study evaluated the superficial microhardness of enamel in teeth at different posteruptive ages (before eruption in the oral cavity, 2-3 years after eruption, 4-10 years after eruption and more than 10 years after eruption). The study sample was composed of 134 specimens of human enamel. One fragment of each tooth was obtained from the flattest central portion of the crown to produce specimens with $3 \times 3 \mathrm{~mm}$. The enamel blocks were minimally flattened out and polished in order to obtain a flat surface parallel to the base, which is fundamental for microhardness testing. Microhardness was measured with a microhardness tester and a Knoop diamond indenter, under a static load of $25 \mathrm{~g}$ applied for 5 seconds. Comparison between the superficial microhardness obtained for the different groups was performed by analysis of Student's $t$ test. The results demonstrated that superficial microhardness values have a tendency to increase over the years, with statistically significant difference only between unerupted enamel and that with more than 10 years after eruption. According to the present conditions and methodology, it was concluded that there were differences between the superficial microhardness of specimens at different eruptive ages, revealing an increasing mineralization. However, this difference was significant only between unerupted specimens and those with more than 10 years after eruption.
\end{abstract}

Descriptors: Dental enamel; Hardness; Tooth eruption; Tooth, unerupted. 


\section{Introduction}

Amongst the problems of oral health, dental caries still constitutes one of the biggest challenges of dentistry. ${ }^{1}$ Its understanding as a multifactorial process leaded researchers to pursue a broader comprehension of it and a search for several methods for its prevention.

Dental caries is a dynamic process that initiates as a located enamel lesion, provoked by alternating periods of demineralization and remineralization. It is caused by intimate contact of the enamel with dental biofilm which is influenced by the oral environment. ${ }^{2,3}$ As an effect of the complexity of this environment, several factors such as the surface of the enamel, the saliva and the presence of dental biofilm, among others, modulate the severity and the development of caries lesions in an individual.

When a tooth erupts in the oral cavity, the enamel has not yet undergone post-eruptive maturation, and presents special characteristics that render it more susceptible to demineralization. ${ }^{4-7}$ At this point, the enamel is more porous, ${ }^{5,8-10}$ with larger carbonated apatite concentration ${ }^{11,12}$ and a greater percentage of impurities (sodium, magnesium, etc) in its composition. ${ }^{13}$ As a consequence, enamel crystals become more soluble in the oral environment. Thus, at eruption, the mineral structures of the enamel are vulnerable to variations of the oral environment. ${ }^{14}$ The saliva, since it presents calcium, phosphorus and fluorine ions - which are the main mineral components of the crystalline structure of the tooth - naturally protects the enamel, favoring the maturation and rendering it less soluble.

Previous studies have shown the different characteristics of the enamel that has not yet undergone post-eruptive maturation from those of enamel that has undergone this type of dynamic in the oral cavity. ${ }^{5,8-12,15}$ However, the nature of this maturation is not well understood. Furthermore, studies have demonstrated that immature enamel is more susceptible to demineralization than mature enamel, $, 6,72,13,16$ probably due to post-eruptive maturation.

Taking those reasons into account, the purpose of this study was to evaluate the superficial microhardness of human enamel with different eruptive ages.

\section{Material and Methods}

This study was approved by the Research and Ethics Committee, School of Dentistry of Bauru, University of São Paulo (Proc. n. 144/2005).

\section{Collection and grouping of the teeth}

Permanent caries-free teeth extracted from patients from a fluoridated area $(0.70 \mathrm{mgF} / \mathrm{L})$ with widely different ages were used. They were collected in the emergency center, School of Dentistry of Bauru, University of São Paulo (FOB-USP), and were divided into 4 groups: Group I - unerupted third molars with incomplete root formation; Group II - premolars extracted for orthodontics reasons with 2-3 years after eruption and with incomplete root formation; Group III - premolars extracted for orthodontics reasons with 4-10 years after eruption and with complete root formation; Group IV - teeth extracted for periodontal or surgical reasons with more than 10 years after eruption. The teeth were stored in a stoppered bottle with a $0.1 \%$ thymol neutral solution.

Teeth with caries, areas of hypomineralization or attrition affecting the enamel and those damaged during extraction were excluded from the study. The teeth finally selected for the study are shown in Table 1 .

\section{Specimen preparation}

In order to produce specimens with $3 \times 3 \mathrm{~mm}$, one fragment of each tooth was obtained from the flattest central portion of the buccal aspect of the crown, which was sectioned with a precision sectioning machine (Isomet Low Speed Saw; Buehler, Lake Bluff, IL, USA) and two double-faced diamond discs (Diamond wafering blade, series $15 \mathrm{HC}$ diamond, arbor size $1 / 2$ inch, Isomet 1000; Buehler,

Table 1 - The 134 teeth used in this study grouped according to their eruptive age.

\begin{tabular}{c|c|c|c|c}
\hline $\begin{array}{c}\text { Age } \\
\text { group }\end{array}$ & $\begin{array}{c}\text { Number } \\
\text { of teeth }\end{array}$ & Teeth & $\begin{array}{c}\text { Eruptive age } \\
\text { (years) }\end{array}$ & Root formation \\
\hline I & 47 & Third molar & Unerupted & Not completed \\
\hline II & 32 & Premolar & 2 to 3 & Not completed \\
\hline III & 29 & Premolar & 4 to 10 & Completed \\
\hline IV & 26 & Different kind & More than 10 & Completed \\
\hline
\end{tabular}


Lake Bluff, IL, USA), separated by a 3-mm spacer adapted to it.

The dentinal aspects of the blocks were initially flattened with silicon carbide paper grit 320 (Buehler, Lake Bluff, IL, USA). Then, the enamel blocks were minimally flattened out (600 and 1,200 grades of $\mathrm{Al}_{2} \mathrm{O}_{3}$ paper; Buehler, Lake Bluff, IL, USA) and polished with felt paper wet by $1 \mu \mathrm{m}$ diamond spray (Buehler), resulting in the removal of about $100 \mu \mathrm{m}$ in depth of the enamel which was controlled with a micrometer.

\section{Microhardness tests}

To investigate the mineral content of the specimens, microhardness tests were performed. The microhardness of the specimens was measured with a microhardness tester (HMV- 2000; Shimadzu Corporation, Tokyo, Japan) and a Knoop diamond indenter, under a static load of $25 \mathrm{~g}$ applied for $5 \mathrm{sec}-$ onds. Five indents were made on each fragment with a distance of $100 \mu \mathrm{m}$.

\section{Statistical analysis}

Comparison of the mean values of the post-eruptive age groups was performed by applying Student's $t$ test. The significance level was set at $5 \%$.

\section{Results}

The values of superficial microhardness found in human enamel with different eruptive ages, unerupted, 2-3 years of eruption, 4-10 years of eruption and with more than 10 years of eruption, are shown in Table 2.

The values of superficial microhardness presented an increasing trend over the years. Significant differ-

Table 2 - Mean microhardness values (KHN) and standard deviation for the human enamel of the studied groups.

\begin{tabular}{l|c|c|c|c}
\hline $\begin{array}{c}\text { Eruptive } \\
\text { age }\end{array}$ & Unerupted & $2-3$ years & $4-10$ years & $\begin{array}{c}\text { More than } \\
10 \text { years }\end{array}$ \\
\hline $\mathrm{N}$ & 47 & 32 & 29 & 26 \\
\hline Mean* & $375.79^{\mathrm{a}}$ & $384.72^{\mathrm{ab}}$ & $383.55^{\mathrm{ab}}$ & $390.69^{\mathrm{b}}$ \\
\hline $\begin{array}{l}\text { Standard } \\
\text { Deviation }\end{array}$ & 21.62 & 14.92 & 16.42 & 11.90 \\
\hline
\end{tabular}

*Means followed by different letters are significantly different $(p<0.05)$. ence was found only between unerupted enamel and that with more than 10 years of eruption $(\rho<0.05)$.

\section{Discussion}

In academic literature, there is no pattern to be considered for age groups in studies regarding posteruptive maturation. This lack of standardization in studies-10,12,13,15-18 generates difficulties for the comparison of results and its trustworthiness.

Therefore, in this study, the collected human teeth presented different post-eruptive ages, and were divided in four groups: Group I - unerupted; Group II - 2-3 years in the oral environment which did not present completely formed roots; Group III - 4-10 years in the oral environment with completely formed roots; and Group IV - more than 10 years in the oral environment. We opted for these age intervals due to the fact that each one of them represents different characteristics, as follows.

The unerupted tooth has never been exposed to the oral environment, its enamel is completely mineralized, and it has not yet undergone post-eruptive maturation.

The 2-3 years interval group includes teeth in the period of eruption or with complete eruption, which already had been exposed to the oral environment. This is a critical period for the development of caries lesions. Since teeth remain long periods in infra-occlusion and children are unable to perform their teeth brushing properly, there is a greater risk of accumulation of dental biofilm. However, teeth in eruption are exposed to dental biofilm during several months before functional occlusion occurs. According to Ekstrand et al..$^{19}$ (2003), the time required for the first and second permanent molars to erupt ranges, respectively, from 5 to 32 and 9 to 45 months.

The 4-10 years interval group presents teeth that already are in occlusal contact and have been exposed to the oral environment for a longer period of time. ${ }^{3}$

The last group, which contains tooth specimens with more than 10 years of eruption, represents those teeth that already are in the oral environment for a much longer period of time.

In the present study, the values of superficial microhardness of the different eruptive age groups 
presented an increasing trend with the increase in age. Significant difference was found only between unerupted enamel specimens and those with more than 10 years of eruption. As known, a direct relation exists between the values of hardness and the percentage of mineral volume. ${ }^{20,21}$ This finding can be related to the exposure of the enamel to the oral-salivary environment ${ }^{14}$ and to normal dynamic processes of demineralization and remineralization during and after the eruptive process. ${ }^{3}$

The results of the present study are in accordance with the findings of $\mathrm{Crabb}^{5}$ (1976), who observed, through reflected light, polarized light and scanning electron microscopy, a defined outer white zone with a honeycomb aspect. He concluded that unerupted or just-after-eruption teeth show a greater susceptibility to demineralization than erupted teeth, as a function of the superficial layer characteristics of the enamel. Brudevold et al. ${ }^{15}$ (1982), albeit following a different methodology, found similar results. They demonstrated that post-eruptive maturation of the enamel involves a reduction in permeability. Furthermore, Fejerskov et al. ${ }^{8}$ (1984), through scanning electron microscopy, observed that the surface of the enamel at the time of eruption presented many varieties of irregularities in its surface, as well as great inter-crystalline spaces, which render the tooth more susceptible to aggression. Still in 1984, Thylstrup et al. ${ }^{22}$ compared unerupted with just-after-eruption teeth. They found small differences between them. The most important was the size of the inter-crystalline spaces, which were smaller in erupted teeth that were exposed to the oral environment.

Driessens et al. ${ }^{13}$ (1985) also have a study which agrees with the present results. They suggested that

\section{References}

1. Lima JEO. Um plano de prevenção para consultório odontopediátrico. Rev Gaúcha Odontol. 1992;40(6):395-9.

2. Dowd FJ. Saliva and dental caries. Dent Clin North Am. 1999;43(4):579-97.

3. Fejerskov O, Nyvad B, Kidd EAM. Características clínicas e histológicas da cárie dentária. In: Fejerskov O, Kidd EAM. Cárie Dentária: a doença e seu tratamento clínico. São Paulo: Santos; 2005. p. 72-96. post-eruptive maturation occurs in minerals of the superficial layer of the enamel, thus producing a greater resistance to caries lesions. Schulte et al. ${ }^{9}$ (1999) and Ten Bosch et al. ${ }^{10}$ (2000) observed an increase in electric resistance with the increase of the post-eruptive ages of the teeth. This characteristic is directly related to a reduction in the porosity of the enamel due to post-eruptive maturation.

It can be suggested that this increasing trend of superficial microhardness could be related to a tendency to be less susceptible to caries over the years. ${ }^{3,5-10,12,14-16}$ Unerupted teeth or with incomplete post-eruptive maturation are more liable to suffer demineralization. ${ }^{6,716}$ However, the fact that the superficial layer of the enamel was polished and flattened, as well as the fact that different kinds of teeth were used, could have influenced the results of the present study.

A better knowledge of post-eruptive maturation, as well as of the natural processes occurring in the enamel soon after eruption, would be an asset to clinical dentists, pediatric dentists and to public health through the definition of preventive strategies, as it would help to recognize the periods of higher susceptibility for the development of new caries lesions.

\section{Conclusion}

The present study revealed differences between the superficial microhardness of specimens with different eruptive ages. The results also indicated an increasing mineralization behavior of enamel. However, significant difference was found only between unerupted enamel specimens and those with more than 10 years of eruption.

4. Baker OD. Posteruptive changes in dental enamel. J Dent Res. 1966;45(Suppl 3):503-11.

5. Crabb HSM. The porous outer enamel of unerupted human premolars. Caries Res. 1976;10(1):1-7.

6. Kotsanos N, Darling AI. Influence of posteruptive age of enamel on its susceptibility to artificial caries. Caries Res. 1991;25(4):241-50. 
7. Woltgens JHM, Bervoets TJM, Witjes F, Driessens FCM. Effect of post-eruptive age on $\mathrm{Ca}$ and $\mathrm{P}$ loss from human enamel during demineralization in vitro. Arch Oral Biol. 1981;26(9):721-5.

8. Fejerskov O, Josephsen K, Nyvad B. Surface ultrastructure of unerupted mature human enamel. Caries Res. 1984;18(4):30214.

9. Schulte A, Gente M, Pieper K. Posteruptive changes of electrical resistance values in fissure enamel of premolars. Caries Res. 1999;33(3):242-7.

10. Ten Bosch JJ, Fennis-le Y, Verdonschol EH. Time-dependent decrease and seasonal variation of the porosity of recently erupted sound dental enamel in vivo. J Dent Res. 2000;79(8):1556-9.

11. Cury JA. Uso do flúor e controle da cárie como doença. In: Baratieri LN. Odontologia restauradora: fundamentos e possibilidades. São Paulo: Santos; 2002. p. 31-68.

12. Gängler P, Norén JG, Hoyer I, Bjarnason S, Kraft U, Odelius $\mathrm{H}$ et al. Reactivity of young and old human enamel to demineralization. Scand J Dent Res. 1993;101(6):345-9.

13. Driessens FCM, Heijligers HJM, Borggreven JMPM, Woltgens JHM. Posteruptive maturation of tooth enamel studied with the electron microprobe. Caries Res. 1985;19(4):390-5.

14. Fanning RJ, Dix FNJ, Shaw JH, Sognnaes RF. Salivary contribution to enamel maturation and caries resistance. J Am Dent Assoc. 1954;49(6):668-71.
15. Brudevold F, Aasenden R, Bakhos Y. A preliminary study of posteruptive maturation of teeth in situ. Caries Res. 1982;16(3):243-8.

16. Woltgens JHM, Bervoets TJM, Witjes F, Driessens FCM. Changes in the comparison of the enamel of human premolar teeth shortly after eruption. Arch Oral Biol. 1981;26(9):7179.

17. Aasenden R. Post-eruptive changes in the fluoride concentrations of human tooth surface enamel. Arch Oral Biol. 1975;20(5-6):359-63.

18. Kidd EAM, Richards A, Thylstrup A, Fejerskov O. The susceptibility of "young" and "old" human enamel to artificial caries in vitro. Caries Res. 1984;18(3):226-30.

19. Ekstrand KR, Christiansen J, Christiansen MEC. Time and duration of eruption of first and second permanent molars: a longitudinal investigation. Community Dent Oral Epidemiol. 2003;31(5):344-50.

20. Arends J, Ten Bosch JJ. Demineralization and remineralization evaluation techniques. J Dent Res. 1992;71(1):924-33.

21. Featherstone JDB, ten Cate JM, Shariati M, Arends J. Comparison of artificial caries-like lesions by quantitative microradiography and microhardness profiles. Caries Res. 1983;17(5):385-91.

22. Thylstrup A, Holmen L, Kragh F. A high-resolution SEM study of unerupted and newly erupted human enamel surfaces [Abstract]. J Ultrastruct Res. 1984;88(3):301. 